\title{
Combined Effects of Surfactant Substitution and Prolongation of Inspiration Phase in Artificially Ventilated Premature Newborn Rabbits
}

\author{
BURKHARD LACHMANN, PER BERGGREN, TORE CURSTEDT, GERTIE GROSSMANN, AND \\ BENGT ROBERTSON ${ }^{(40)}$ \\ Department of Pathophysiology, Research Institute for Lung Diseases, Berlin-Buch, German Democratic Republic, \\ Departments of Pediatric Pathology and Pediatrics, St. Görans Children's Hospital, and Department of Clinical \\ Chemistry, Karolinska Hospital, Stockholm, Sweden
}

\begin{abstract}
Summary
Premature newborn rabbits, delivered by hysterotomy on day 27 of gestation, were tracheotomized at birth, kept in body plethysmographs, and subjected to pressure-generated ventilation at a working pressure of $25 \mathrm{~cm} \mathrm{H} \mathrm{H}_{2} \mathrm{O}, 100 \% \mathrm{O}_{2}$, and frequency $40 / \mathrm{min}$. Thirty-seven animals received $50 \mu \mathrm{l}$ of heterologous surfactant (phospholipid content $40 \mathrm{mg} / \mathrm{ml}$ ) via the tracheal cannula before onset of artificial ventilation, eight were ventilated with a positive end-expiratory pressure (PEEP) of $6 \mathrm{~cm} \mathrm{H} \mathrm{H}_{2} \mathrm{O}$, and 44 served as controls. All animals were ventilated in a randomized sequence of 2-min periods with $20,40,60$, or $80 \%$ inspiration time. After the experiment the trachea was clamped at end-inspiration and the lungs fixed by immersion in formalin. Plethysmograph recordings of tidal volume revealed that lung-thorax compliance was low in control animals, even at inspiration time $80 \%($ mean \pm S.E. $=0.17$ $\pm 0.03 \mathrm{ml} / \mathrm{cm} \mathrm{H}_{2} \mathrm{O} \cdot \mathrm{kg}$ ). In animals treated with surfactant or PEEP, compliance was significantly improved at all ventilator settings. The highest mean compliance values, obtained at $60 \%$ inspiration time were $0.91 \pm 0.07$ and $0.73 \pm 0.14 \mathrm{ml} / \mathrm{cm} \mathrm{H}_{2} \mathrm{O} \cdot \mathrm{kg}$ in surfactant- and PEEP-treated animals, respectively. Compliance of surfactant-treated animals was significantly higher than that of PEEP-treated animals at inspiration time $40 \%(0.85 \pm 0.07$ versus $\left.0.52 \pm 0.13 \mathrm{ml} / \mathrm{cm} \mathrm{H}_{2} \mathrm{O} \cdot \mathrm{kg} ; P<0.05\right)$. The relative volume of the alveolar compartment, determined morphometrically in histologic sections and expressed as the alveolar expansion index $\left(I_{a}\right)$, was significantly higher in surfactant-treated animals than in controls $(1.60 \pm 0.12$ versus $0.74 \pm 0.06 ; P<0.005)$, but not improved in animals ventilated with PEEP. In animals receiving surfactant, $I_{a}$ increased with the duration of the inspiration phase, from $0.99 \pm 0.10$ at $20 \%$ to $1.95 \pm 0.22$ at $80 \%$ inspiration time. There was also histologic evidence of enhanced recruitment of aerated alveoli in surfactant-treated animals ventilated with prolonged inspiration time.
\end{abstract}

\section{Speculation}

The air expansion of the premature neonatal lung can be enhanced to a significant degree by treatment with surfactant in combination with appropriate prolongation of the inspiration phase. Such a therapeutic regimen might be useful in the management of newborn infants with severe respiratory distress syndrome, requiring artificial ventilation; however, because excessive prolongation of the inspiration phase could have adverse effects on pulmonary hemodynamics and lead to hypoventilation with respiratory acidosis, the setting of the ventilator should be carefully adjusted with respect to the therapeutic response in patients with respiratory distress syndrome who are treated with supplementary surfactant.
Ventilation of the wet neonatal lung has to overcome resistance due to surface tension, viscosity of fetal pulmonary fluid, and tissue elasticity $(2,3)$. In an immature lung with surfactant deficiency, the resistance due to capillarity in finer conducting airways necessitates a high opening pressure $(2,15,20)$. Lungs with surfactant deficiency also tend to collapse at end-expiration, which means that the same high opening pressure has to be applied at each inspiration. This is the pathophysiologic mechanism of the neonatal respiratory distress syndrome (RDS) (37).

In previous experiments, we have shown that lung-thorax compliance of the artificially ventilated premature rabbit neonate can be significantly improved by tracheal instillation of natural surfactant (for review, see 35) or by prolongation of the inspiration phase (23). Both these therapeutic measures have been applied separately in clinical trials on patients with severe RDS, with favorable results $(18,21,32)$.

The purpose of the present study was to test, in experiments on artificially ventilated premature newborn rabbits, the combined effects of surfactant treatment and prolongation of the inspiration phase. The main parameters evaluated were lung-thorax compliance and alveolar expansion in histologic sections from lung preparations fixed at end-inspiration.

\section{MATERIALS AND METHODS}

Preparation and in vitro analysis of surfactant. The surfactant was obtained by washing the lungs of adult pigs with saline. After removal of contaminating cells by centrifugation at $500 \times \mathrm{g}, 10$ $\min , 20^{\circ} \mathrm{C}$, the supernatant was recentrifuged at $1000 \times \mathrm{g}, 1 \mathrm{~h}$, $4^{\circ} \mathrm{C}(15)$. The resulting pellet was resuspended in saline and further centrifuged over $0.68 \mathrm{M}$ sucrose (17) at $7500 \times \mathrm{g}, 1 \mathrm{~h}$, $20^{\circ} \mathrm{C}$, to separate the phospholipid and protein components. The lipids floating in the sucrose-saline interface were harvested; this pellicle, used for tracheal instillation in the in vivo experiments, had a phospholipid concentration of $40 \mathrm{mg} / \mathrm{ml}$. Its protein content, determined according to Lowry et al. (26) after saponification of the phospholipids with $2 \mathrm{M} \mathrm{NaOH}$ was $<1 \mathrm{mg} / \mathrm{ml}$.

The phospholipids were isolated by reversed phase chromatography on a column of Lipidex-5000 (9). After fractionation into nonacidic and acidic phospholipids by chromatography on a lipophilic anion exchanger (10), the different classes of phospholipids were isolated by thin-layer chromatography (31). The concentration and composition of phospholipids were performed by phosphorus determination according to the method of Bartlett (5). The composition of molecular species of the different classes of phospholipids was determined after hydrolysis with phospholipase C. The 1,2-diacylglycerols formed were analysed as trimethylsilyl ethers by capillary gas-liquid chromatography. These analyses were carried out on a Fractovarp 4160 gas chromatograph (Carlo 
Erba Strumentazione, Milan, Italy) equipped with a flame ionization detector, an on-column injector, and housing a $25 \mathrm{~m}$ opentubular glass capillary column coated with OV-1. The gas-chromatographic peak areas were calculated by a Varian CDS 401 integrator (Varian Associates, Inc., Walnut Creek, CA, USA). Some of the samples were also analysed by a Finnigan 1020 gas chromatograph-mass spectrometer (Finnigan Corporation, Sunnyvale, CA, USA) using a $10 \mathrm{~m} \mathrm{OV-l} \mathrm{glass} \mathrm{capillary} \mathrm{column.} \mathrm{The}$ phospholipid data for our final preparation, shown in Tables 1 and 2, are close to those of an optimal "artificial" lung surfactant as recently defined by Fujiwara et al. $(16,19)$.

The surface properties of our surfactant preparation, analysed with pulsating bubble (12), were characterized by very rapid adsorption of the phospholipids to the air-liquid interface and zero surface tension at minimal bubble size (Fig. 1).

Animal experiments. These experiments were carried out on a total of 89 premature newborn rabbits from ten litters, delivered on day 27 of gestation (day of copulation $=$ day 0 ; full term $=31$ \pm 1 days). The rabbit does were anesthetized by intravenous injections of sodium hexobarbital (Hexobarbital-Natrium, VEB Arzneimittelwerk, Dresden, German Democratic Republic, 100 $\mathrm{mg} / \mathrm{ml}$, total dose: $500-700 \mathrm{mg}$ ), and laparotomized. In eight litters, the fetuses were delivered in sequence and immediately tracheotomized, with a metal cannula as tracheal tube. Every second fetus ( $n=37$; body weight $=35 \pm 5$ g, mean \pm S.D.) received $50 \mu \mathrm{l}$ of natural surfactant in the tracheal cannula. In littermate controls $(n=38$; body weight $=35 \pm 5 \mathrm{~g}$ ) the tracheal cannula was empty.

When all animals had been tracheotomized, they were relaxed by intraperitoneal injection of $0.1 \mathrm{ml}$ pancuronium bromide ( $\mathrm{Pa}$ -

Table 1. Composition of phospholipids in surfactant

\begin{tabular}{lc}
\hline \multicolumn{1}{c}{ Phospholipids } & moles \% \\
\hline Phosphatidylcholine & 88.4 \\
Phosphatidylethanolamine & 2.2 \\
Phosphatidylserine & 0.9 \\
Phosphatidylinositol & 4.4 \\
Phosphatidylglycerol & 2.5 \\
Cardiolipin & 0.3 \\
Sphingomyelin & 1.0 \\
Lysophospholipids & 0 \\
Other phospholipids & 0.3 \\
\hline
\end{tabular}

vulon, $2 \mathrm{mg} / \mathrm{ml}$, diluted 1:10, Organon, Holland) and transferred to a multiple-chamber, pressure-constant body plethysmograph, heated to $37^{\circ} \mathrm{C}(23)$. The tracheal cannulas were connected to a respirator system, based on a modified Servo Ventilator $900 \mathrm{~B}$ (Siemens-Elema, Solna, Sweden). The animals were ventilated in parallel with $100 \% \mathrm{O}_{2}$ at a frequency of $40 / \mathrm{min}$. Minute volume was set at $7 \mathrm{l} / \mathrm{min}$, which means that a pressure-generated ventilation with decelerating flow was established. During the first min, a working pressure of $35 \mathrm{~cm} \mathrm{H}_{2} \mathrm{O}$ was applied to all animals in order to overcome initial resistance to aeration due to capillarity in the smaller conducting airways; during this phase of the experiment all animals were ventilated with 50\% inspiration time. To avoid pneumothorax, working pressure was then lowered to 25 $\mathrm{cm} \mathrm{H}_{2} \mathrm{O}$ throughout the period of ventilation, and inspiration times of $20,40,60$, and $80 \%$ were applied for 2 min each, in a randomized sequence in all animals.

Tidal volume $\left(\mathrm{V}_{\mathrm{T}}\right)$ at the end of the 2-min interval was determined for each animal with a specially designed Fleisch-tube (24) connected to the body plethysmograph, a differential pressure transducer (Siemens-Elema EMT 34), an amplifier (SiemensElema EMT 31), an integrator unit (Siemens-Elema EMT 41), and a recorder (Siemens-Elema Mingograf 800).

In two litters, not receiving surfactant, a positive end-expiratory pressure (PEEP) of $6 \mathrm{~cm} \mathrm{H} \mathrm{H}_{2} \mathrm{O}$ was applied in every second animal $(n=8$; body weight $=39 \pm 4 \mathrm{~g})$, from the onset of ventilation and throughout the experiment. The procedure was otherwise the same as described above. Littermate controls ( $n=6$; body weight $=39$ $\pm 2 \mathrm{~g}$ ) were ventilated in parallel. The difference in mean body weight between these two litters and litters treated with surfactant is not statistically significant $(P>0.05)$.

At the end of the experiment the animals received an overdose of intraperitoneal sodium hexobarbital $(50 \mathrm{mg})$ and were exsanguinated by transection of the abdominal aorta. The sacrificed animals were ventilated with air for $5 \mathrm{~min}$ with the same ventilator setting as during the preceding 2 -min period, i.e., with inspiration time varying between $20-80 \%$, and the tracheal tube was then clamped at end-inspiration. The diaphragm was inspected for evidence of pneumothorax. The unopened thorax was fixed by immersion in $10 \%$ formalin and embedded in paraffin. Transverse sections were cut at the level of the cardiac ventricles and stained with hematoxylin and eosin. These sections were examined in the light microscope, with particular reference to alveolar expansion and bronchiolar epithelial lesions. The relative number of aerated

Table 2. Molar percentage composition of molecular species of different phospholipids in surfactant

\begin{tabular}{|c|c|c|c|c|c|}
\hline $\begin{array}{l}\text { Acyl and alkyl carbons: } \\
\text { double bonds }\end{array}$ & Major molecular species & $\begin{array}{l}\text { Phosphatidyl- } \\
\text { cholines }\end{array}$ & $\begin{array}{l}\text { Phosphatidyl- } \\
\text { ethanolamines }\end{array}$ & $\begin{array}{l}\text { Phosphatidyl- } \\
\text { inositols }\end{array}$ & $\begin{array}{l}\text { Phosphatidyl- } \\
\text { glycerols }\end{array}$ \\
\hline $30: 0$ & & 9.8 & 1.9 & 0.2 & 3.5 \\
\hline $31: 0$ & & 1.2 & 0.5 & & 0.4 \\
\hline $32: 1$ & 1-palmitoyl-2-palmitoleoyl & 8.8 & 2.4 & 2.7 & 6.2 \\
\hline $32: 1-2$ & 1-myristoyl-2-oleoyl & 4.4 & 0.3 & 0.4 & 1.0 \\
\hline $34: 0$ & & 3.6 & & & \\
\hline $34: 1^{2}$ & 1-hexadec-1'-enyl-2-oleoyl & & & & \\
\hline $34: 2^{2}$ & 1-hexadec-1'-enyl-2-linoleoyl & & 3.9 & & \\
\hline $36: 1$ & 1-stearoyl-2-oleoyl & & & & \\
\hline $36: 2$ & 1-stearoyl-2-linoleoyl & 1.1 & 19.8 & 19.8 & 8.6 \\
\hline $38: 0-6$ & & & 2.4 & 8.5 & \\
\hline Not identified & & 1.7 & 6.4 & 2.7 & 7.3 \\
\hline
\end{tabular}

${ }^{1}$ Not including the double bond between $\mathrm{C}-1$ and $\mathrm{C}-2$ in the alkyl chain.

${ }^{2}$ Ether analogues (plasmalogens). 
alveoli was estimated semiquantitatively according to a five-grade scale $(0,1-25,26-50,51-75$, and $>75 \%)$ and the alveolar expansion index $\left(\mathrm{I}_{\mathrm{a}}\right)$ was determined morphometrically by point-counting (13). The histologic examination was performed without knowledge of the experimental conditions of the individual animals.

Statistical evaluation. The Chi-square test and the Wilcoxon two-sample test, two-tailed, were used for statistical evaluation of the results.

\section{RESULTS}

All experimental animals and controls survived the recording procedure, as judged from pulsatile blood flow in the aorta at the end of the experiment. None of the animals developed pneumothorax.

Lung-thorax compliance. In general, compliance values for animals treated with surfactant were 4-5 times higher than those of controls (Table 3). Another striking difference between these groups was that whereas compliance values for control animals remained at the same low level at each ventilator setting, compliance of surfactant-treated animals increased when inspiration time was prolonged from 20 to $40 \%(P<0.01)$. An even higher mean compliance value was obtained at $60 \%$ inspiration time. Prolongation of inspiration time to $80 \%$ did not lead to further improvement in compliance; on the contrary, mean compliance value for this ventilator setting was slightly lower than for inspiration time $60 \%$. These latter differences within the surfactant-treated group were, however, not statistically significant. Representative tracings from surfactant-treated animal and littermate control are shown in Figure 2 (upper panel).

Lung-thorax compliance in animals treated with PEEP was also clearly improved in comparison with the control group (Table 3) but did not quite reach the same high values as noted in surfactanttreated animals. The difference between animals receiving surfac-

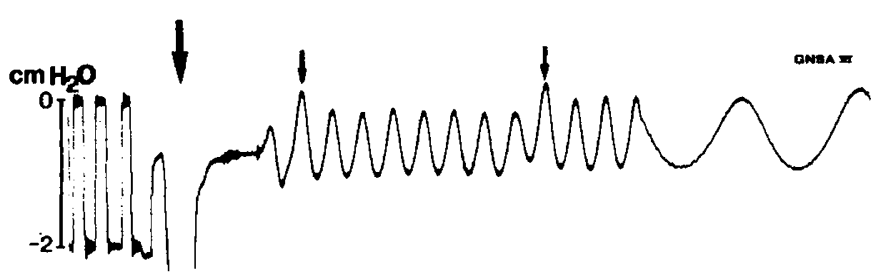

$\min \max$

Fig. 1. Original pressure tracing from an open bubble pulsating in our surfactant preparation at $37^{\circ} \mathrm{C}$. Large arrow indicates when the bubble is formed; note quick stabilization of the pressure gradient across the bubble wall before onset of pulsation, indicating rapid film adsorption. During regular pulsation, the radius of the bubble oscillates between $0.52-0.43$ $\mathrm{mm}$, at the rate of $20 / \mathrm{min}$. Small arrows indicate irregular pulsations after which the bubble size is corrected. Max and min refer to maximal and minimal bubble size. After $45 \mathrm{sec}$ of pulsation, the pressure gradient across the bubble wall is zero at minimal bubble size; this corresponds to zero surface tension.

Table 3. Lung-thorax compliance at various inspiration times, in animals treated with surfactant or positive end-expiratory pressure $(P E E P)\left(6 \mathrm{~cm} \mathrm{H}_{2} \mathrm{O}\right)$, and in littermate controls

\begin{tabular}{lrcccc}
\hline & \multicolumn{5}{c}{ Compliance $\left(\mathrm{ml} / \mathrm{cm} \mathrm{H}_{2} \mathrm{O} \cdot \mathrm{kg}\right.$; mean \pm S.E. $) /$ inspiration } \\
time $(\%)$
\end{tabular}

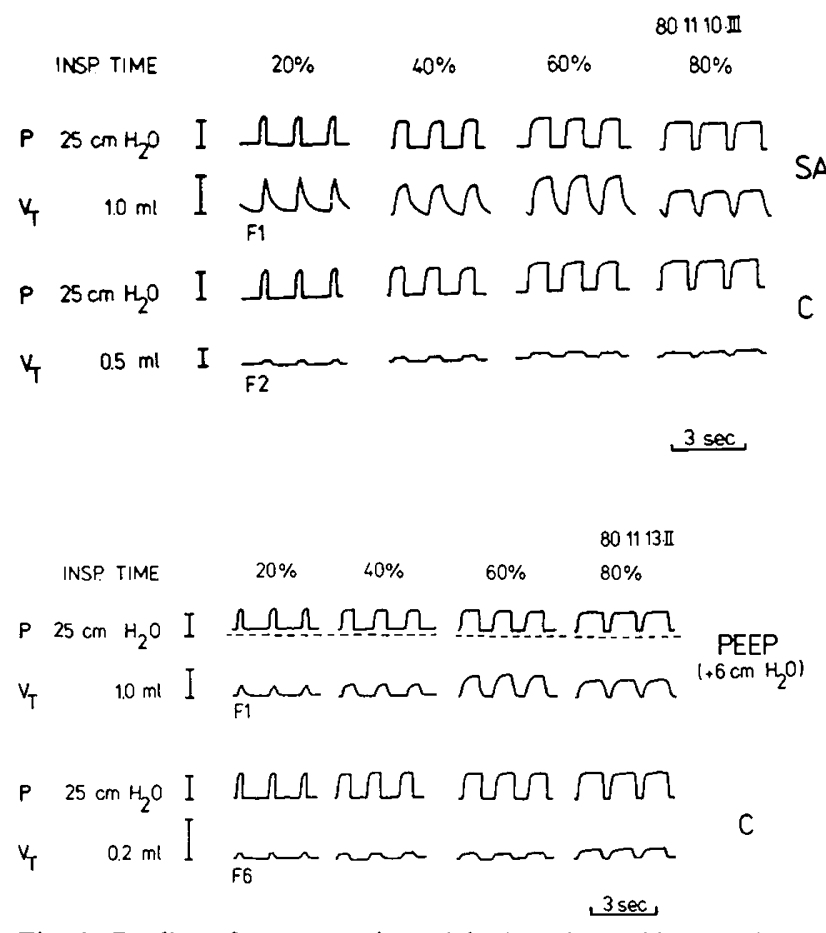

Fig. 2. Replica of representative original tracings of insufflation pressure $(\mathrm{P})$ and tidal volume $\left(\mathrm{V}_{\mathrm{T}}\right)$ in two experiments, showing the prominent effects of treatment with surfactant $(S A)$ or positive end-expiratory pressure $(P E E P)$. At all ventilator settings, the surfactant- (upper panel) or PEEP-treated (lower panel) animals have much larger $\mathrm{V}_{\mathrm{T}}$ than their littermate controls (C), and in both treated animals the effect is most striking at inspiration time $60 \%$. Note also that the volume tracing of the surfactant-treated animal shows a prolonged expiration phase; the appearance of this "mature"type of volume tracing is a typical result of surfactant treatment ( $c f .27)$.

tant and those treated with PEEP was statistically significant only for inspiration time 40\% $(P<0.05)$. Representative tracings from PEEP-treated animal and littermate control are shown in Figure 2 (lower panel).

Histologic-morphometric findings. Semiquantitative evaluation of alveolar aeration revealed a striking difference between surfactant-treated animals and controls. In the majority of the treated animals $(25 / 37)$ more than $50 \%$ of the parenchyma was well aerated, whereas only few of the control animals $(3 / 44)$ had a corresponding degree of alveolar air expansion $(P<0.001)$. In the majority of the control animals $(30 / 44)$, the parenchyma was completely nonaerated, and the alveoli had retained the configuration characteristic of the fluid-filled fetal lung (Fig. 3A). Animals treated with PEEP showed no histologic evidence of improved alveolar air expansion. The semiquantitative findings are corroborated by the morphometric data shown in Table 4; the mean alveolar expansion index is here more than twice as high in the surfactant-treated group as in controls or in animals ventilated with PEEP.

In surfactant-treated auimals, there was also a correlation between alveolar expansion in histologic sections and the duration of the inspiration phase. Semiquantitative evaluation of the sections showed increased recruitment of alveoli in surfactant-treated animals ventilated with prolonged inspiration phase, particularly in those ventilated with 60 and $80 \%$ inspiration time. In most (10/ 19) of the surfactant-treated animals ventilated with inspiration time $20-40 \%$, less than $50 \%$ of the parenchyma appeared aerated in the histologic sections (Fig. 3B) whereas in animals ventilated with $60-80 \%$ inspiration time a definite majority $(16 / 18)$ had alveolar air expansion involving more than $50 \%$ of the parenchyma $(P<0.02)$. In 12 of these latter animals, more than $75 \%$ of the parenchyma was well aerated (Fig. $3 \mathrm{C}$ and D). In the control group, variations in the alveolar expansion pattern were not 


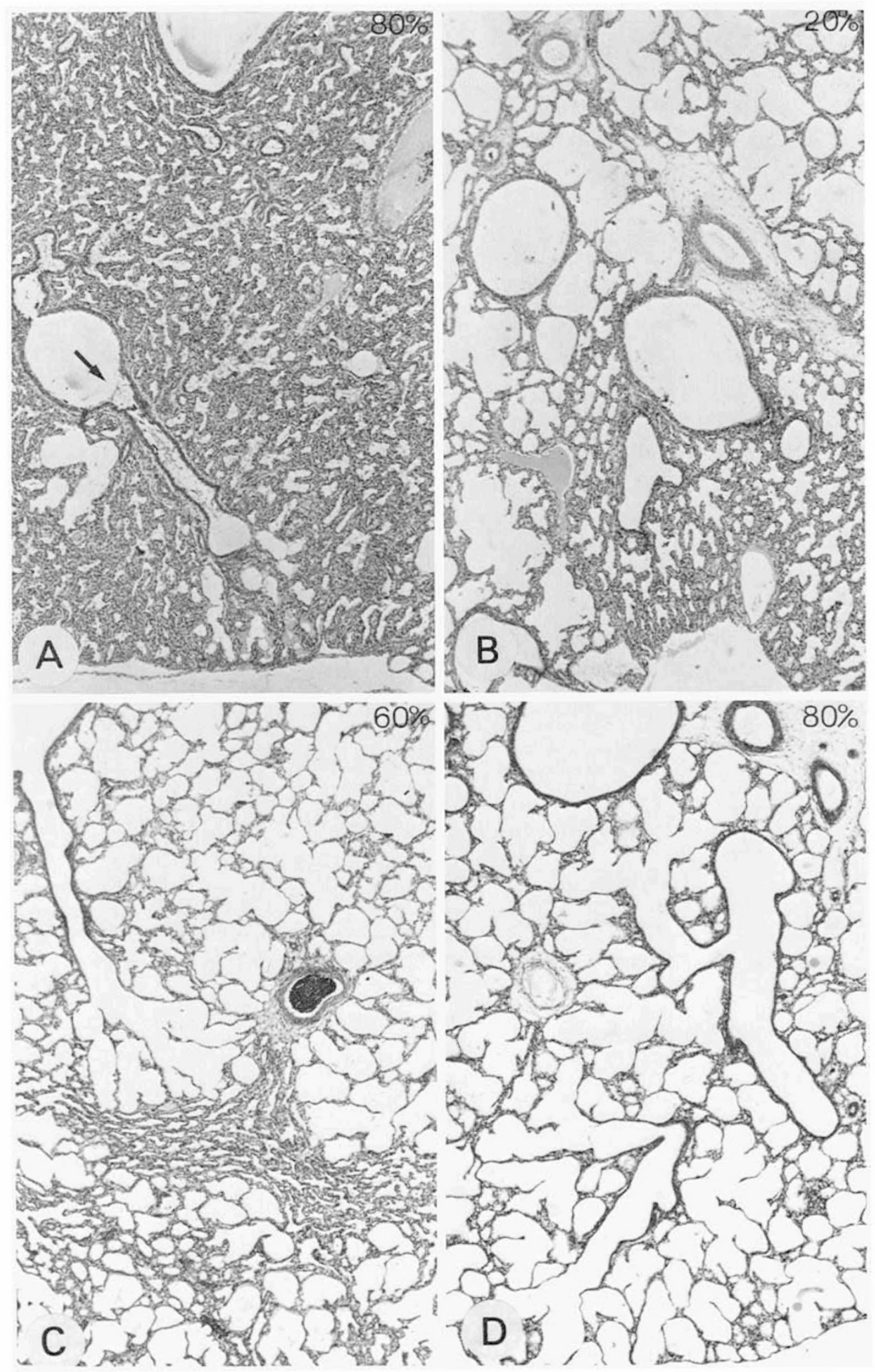

Fig. 3. Histologic lung sections from control animal, ventilated with inspiration time $80 \%(A)$, and surfactant-treated animals ventilated with inspiration time $20 \%(B), 60 \%(C)$, and $80 \%(D)$. In all animals the trachea was clamped at end-inspiration before immersion fixation. In the control animal, only few alveoli are aerated and an air-liquid interface is clearly visible in the opening of a terminal bronchiole (arrow). The same bronchiole contains numerous necrotic, desquamating epithelial cells ( $c f$. Fig. 6A). Among the surfactant-treated animals, some degree of alveolar air expansion is seen already at inspiration time $20 \%$, and there is increasing recruitment of aerated alveoli in animals ventilated with $60 \%$ and $80 \%$ inspiration time. No bronchiolar epithelial lesions are present in these surfactant-treated animals. Hematoxylin and eosin, $\times 44$.

correlated to the duration of the inspiration phase. A diagram summarizing these semiquantitive data is given in Figure 4.

As shown in Figure 5, mean $I_{a}$ was about 1.7 times higher in surfactant-treated animals ventilated with $40 \%$ than in those ven- tilated with $20 \%$ inspiration time, and there was some additional increase of $I_{a}$ in animals ventilated with 60 and $80 \%$ inspiration time. Differences in $I_{a}$ within the control group were not statistically significant. 
Table 4. Alveolar expansion index $\left(I_{a}\right)$ in animals treated with surfactant or positive end-expiratory pressure (PEEP) and in littermate controls

\begin{tabular}{lrrlc}
\hline & & \multicolumn{2}{c}{$P$ versus } \\
\cline { 4 - 5 } Treatment & $n$ & $\mathrm{I}_{\mathrm{a}}$ (mean \pm S.E.) & Controls & $\begin{array}{c}\text { PEEP-treated } \\
\text { animals }\end{array}$ \\
\hline Surfactant & 37 & $1.60 \pm 0.12$ & $<0.005$ & $<0.005$ \\
PEEP & 8 & $0.63 \pm 0.12$ & NS & NS \\
Controls & 44 & $0.74 \pm 0.06$ & & N \\
\hline
\end{tabular}
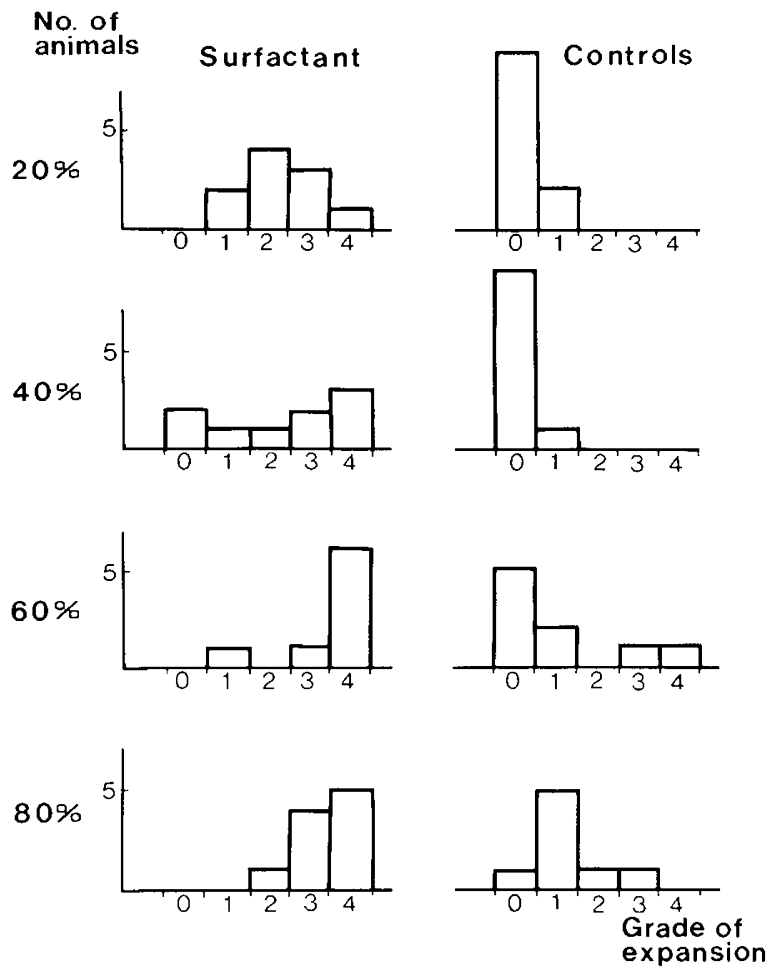

Fig. 4. Diagram based on data from semiquantitative evaluation of alveolar air expansion in surfactant-treated animals and controls, ventilated with various inspiration times $(20,40,60$, and $80 \%)$. The relative number of aerated alveoli was estimated in histologic sections and graded as follows: $0: 0 \%, 1: 1-25 \%, 2: 26-50 \%, 3: 51-75 \%$, and $4:>75 \%$ air-expanded alveoli. Note increasing recruitment of air-expanded parenchyma in surfactant-treated animals ventilated with prolonged inspiration time. Additional comments and statistical evaluation is given in the text. Representative histologic sections are shown in Figure 3.

In the majority of the control animals (30/44) there was widespread necrosis and desquamation of the bronchiolar epithelium, most probably induced by the period of artificial ventilation (29) (Fig. 6A). In the surfactant-treated group, on the other hand, only few animals $(11 / 37)$ had such lesions $(P<0.001)$ (Fig. 6B). When present in surfactant-treated animals, the epithelial lesions characteristically affected only nonaerated portions of the lungs. Half of the eight animals ventilated with PEEP showed evident necrosis and desquamation of bronchiolar epithelium, but in the remaining four PEEP-treated animals no such lesions were found.

\section{DISCUSSION}

The "opening pressure" of the neonatal lung can be defined as the pressure level required to move the air-liquid interface through the respiratory bronchioles. In surfactant-deficient neonatal rabbit lungs, this critical pressure level is on the order of $30 \mathrm{~cm} \mathrm{H}_{2} \mathrm{O}$. Immature newborn rabbits, delivered on day 27 of gestation and ventilated with this pressure, show a striking increase in lungthorax compliance with increasing inspiration time (23). This
Surfactant-treated $\square$ Controls

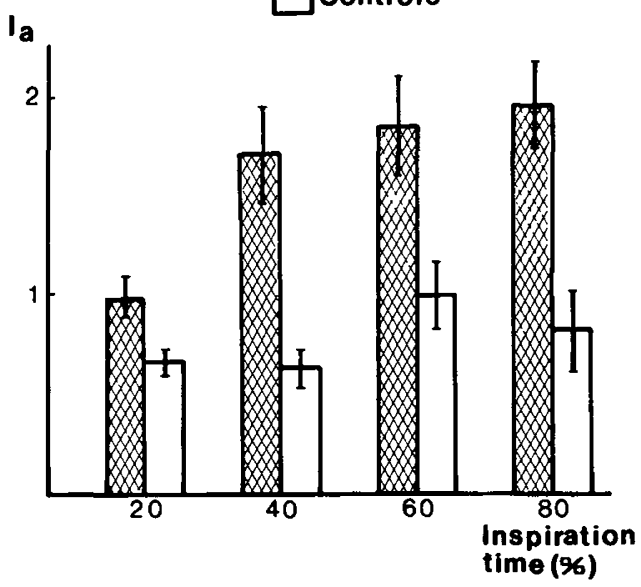

Fig. 5. Alveolar expansion index (mean \pm S.E.) in surfactant-treated animals and controls, related to the duration of the inspiration phase. In the surfactant-treated animals, each of the mean values obtained at 40,60, and $80 \%$ inspiration time is significantly higher than the mean value for $20 \%$ inspiration time $(P<0.05,0.01$, and 0.01 , respectively). Differences within the control group are not statistically significant.

illustrates that air expansion of the lungs is indeed possible once adequate time is allowed for displacement of fluid from the airways. If such immature animals are ventilated with a pressure of only $25 \mathrm{~cm} \mathrm{H}_{2} \mathrm{O}$, as in the present study, lung compliance has the same low level at all ventilator settings; these lungs are thus ventilated with a pressure that is too low to open the terminal airspaces, irrespective of the duration of the inspiration phase. Data given in Table 3 also show that the critical opening pressure can be reduced by tracheal instillation of surfactant. Animals receiving this treatment could be ventilated effectively with a pressure of 25 $\mathrm{cm} \mathrm{H}_{2} \mathrm{O}$, even with a comparatively short inspiration time. Both the compliance figures and the morphometric data (Fig. 5) indicate, however, that alveolar expansion improves significantly also in surfactant-treated animals when the inspiration time is prolonged from 20 to $40 \%$.

Surfactant phospholipids facilitate air expansion in the neonatal lung by two basic mechanisms. By lowering surface tension of fetal pulmonary fluid, these lipids reduce the resistance to aeration that is due to capillarity in the finer conducting airways and, hence, the pressure level required for the initial expansion of terminal airspaces $(15,34)$. Moreover, the same lipids generate a stabilizing film in the air-liquid interface, which prevents alveolar collapse at end-expiration $(4,7)$. Alveoli already open do not require a prolonged inspiration phase to expand, nor do already stabilized alveoli require a short expiration phase to remain patent. This explains why surfactant-treated animals could be well ventilated with a low peak pressure and a short inspiration phase, and why bronchiolar epithelial lesions-the equivalent of early hyaline membrane disease $(29,36)$-were usually absent in animals receiving surfactant. In the artificially ventilated surfactant-deficient lung, such lesions seem to result from shear forces in the bronchiolar mucosa, secondary to overexpansion of bronchioles and uneven expansion of terminal airspaces during the ventilatory cycle (30).

The present findings confirm earlier observations that treatment of the premature lung with PEEP leads to increased lung compliance (28). Most probably, the mechanism is here similar to that operating in surfactant-treated animals, i.e., the continuous positive pressure keeps the alveoli open throughout the ventilatory cycle, and resistance to aeration due to capillarity in finer conducting airways is thereby avoided. The protocol of our present experiments implied that all animals were initially ventilated for 1 min with a pressure well above the expected opening pressure. During this period some degree of alveolar air expansion was 


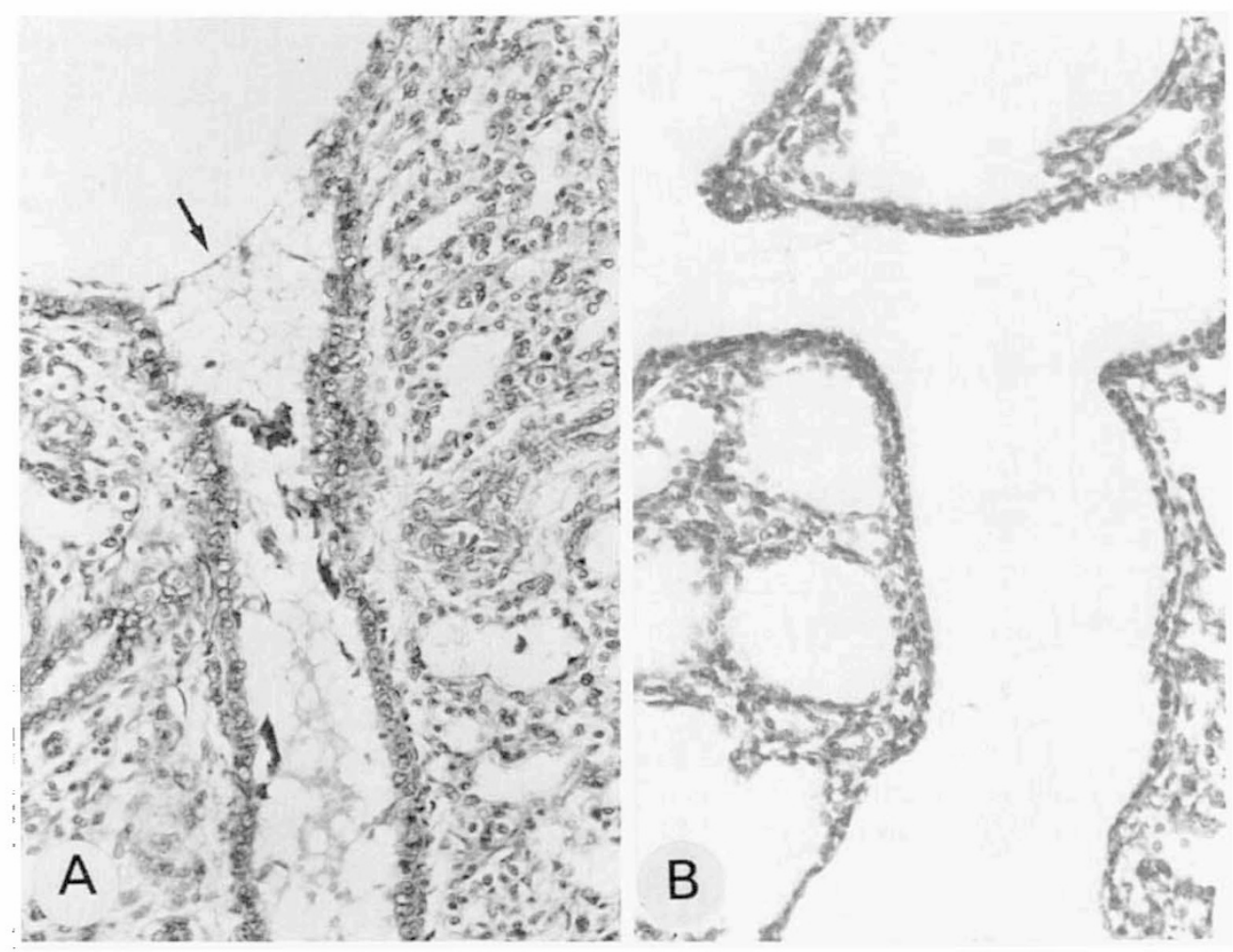

Fig. 6. Details of Figures $3 A$ and $D$ show the structure of bronchiolar epithelium in control and surfactant-treated animals, littermates both ventilated with inspiration time $80 \%$. In the control animal $(A)$, the epithelium of a liquid-filled bronchiole shows prominent necrosis and desquamation; the airliquid interface in the proximal opening of the bronchiole is indicated with arrow. The surfactant-treated animal $(B)$ has well preserved bronchiolar epithelium. Hematoxylin and eosin, $\times 220$.

probably achieved in all animals, including the surfactant-deficient ones. In animals treated with PEEP, end-expiratory collapse did not occur; these animals could therefore be ventilated with a comparatively low insufflation pressure $\left(25 \mathrm{~cm} \mathrm{H}_{2} \mathrm{O}\right)$ during the next phase of the experiment and respond to increasing inspiration time with a rise in lung-thorax compliance.

In animals treated with PEEP, there is an apparent discrepancy between the data on lung-thorax compliance and the histologic findings. Whereas compliance was clearly improved in these animals, semiquantitative and morphometric evaluation of alveolar expansion revealed no difference versus controls - despite the fact that the lungs were fixed at end-inspiration. This discrepancy is due to the fact that surfactant-deficient neonatal lungs will show postmortem collapse, even if the lungs are fixed at end-inspiration after ventilation with high insufflation pressure and prolonged inspiration; air-expanded alveoli covered with surfactant, on the other hand, will remain patent during immersion fixation (25).

Our data on lung-thorax compliance suggest that the effect of PEEP might be inferior to that obtained with tracheal instillation of surfactant, although a statistically significant difference between these two groups was found only for inspiration time $40 \%$. Ventilation with PEEP has a well documented beneficial effect on blood gases, lung morphology and survival in surfactant-deficient patients $(6,8,11,21,33)$. In pressure-generated ventilation, however, this form of treatment carries a risk of alveolar hypoventilation with ensuing retention of $\mathrm{CO}_{2}$; this holds particularly if PEEP is raised to the order of $10 \mathrm{~cm} \mathrm{H}_{2} \mathrm{O}$ (21). Such a complication is unlikely to occur after treatment with surfactant, provided that the inspiration time is kept within the optimal range.

The effects of surfactant treatment and PEEP at various ventilator settings have, of course, to be further documented by direct measurements of blood gases. So far, our attempts to obtain arterial blood samples during artificial ventilation have been unsuccessful in these small experimental animals. Experience from RDS-models in larger animals such as lambs $(1,22)$ and monkeys
(14) have shown that treatment with surfactant via the airways has a clearly beneficial influence on both $\mathrm{PaO}_{2}$ and $\mathrm{PaCO}_{2}$, even at conventional ventilator settings.

The combined evidence of the present and previous experimental studies thus indicates that tracheal instillation of surfactant should be effective in neonatal RDS, especially as this treatment circumvents the adverse circulatory effects that might be induced by high insufflation pressure, high PEEP levels, and very long inspiration phase, which is a combination of therapeutic regimens that has to be applied in some RDS patients to ensure adequate arterial oxygenation. A recent clinical trial, in which a mixture of natural and synthetic surfactants was administered into the airways of patients with severe RDS, supports the validity of this conclusion (18). Our data furthermore show that following treatment with surfactant, adequate $V_{T}$ can be maintained in the immature animals with an inspiration time of $40-60 \%$. Because unnecessary prolongation of the inspiration phase could have adverse effects on pulmonary hemodynamics and lead to hypoventilation the setting of the respirator should be carefully adjusted with respect to the therapeutic response in RDS-patients treated with supplementary surfactant.

\section{REFERENCES AND NOTES}

1. Adams, F. H., Towers, B., Osher. A. B., Ikegami, M., Fujiwara, T., and Nozaki M.: Effects of tracheal instillation of natural surfactant in premature lambs. $\mathrm{I}$. Clinical and autopsy findings. Pediatr. Res., 12: 841 (1978).

2. Agostoni, E., Taglietti, A., Agostoni, A., and Setnikar, I.: Mechanical aspects of the first breath. J. Appl. Physiol., 13: 344 (1958).

3. Avery, M. E., Fletcher, B. D., and Williams, R. G.: The lung and its disorders in the newborn infant. p. 29. (Saunders, Philadelphia, 4th ed.. 1981).

4. Bangham, A. D.. Morley, C. J., and Phillips, M. C.: The physical properties of an effective lung surfactant. Biochim. Biophys. Acta., 573: 552 (1979).

5. Bartlett, G. R.: Phosphorus assay in column chromatography. J. Biol. Chem., 234: 466 (1959).

6. Berg, T. J., Pagtakhan, R. D., Reed, M. H., Langston, C., and Chernick, V.: Bronchopulmonary dysplasia and lung rupture in hyaline membrane disease: 
influence of continuous distending pressure. Pediatrics, 55: 51 (1975).

7. Clements, J. A.: Functions of the alveolar lining. Amer. Rev. Resp. Dis., 115: 67 (1977).

8. Cumarasamy, N., Nüssli, R., Vischer, D., Dangel, P. H., and Duc. G. V.: Artificial ventilation in hyaline membrane disease: the use of positive end-expiratory pressure and continuous positive airway-pressure. Pediatrics, 51: 629 (1973).

9. Curstedt, T.: Biosynthesis of molecular species of phosphatidylcholines in bile liver and plasma of rats given $\left(1,1-{ }^{2} \mathrm{H}_{2}\right)$ ethanol. Biochim. Biophys. Acta., 369: 196 (1974).

10. Curstedt, $\Upsilon$.: Isolation of different classes of hepatic phospholipids by liquid chromatography on Lipidex gels. To be published.

11. DeLemos, R. A.. McLaughlin, G. V., Robinson, E. J., Schultz, J., and Kirby, R. R.: Continuous positive airways pressure as adjunct to mechanical ventilation in the newborn with respiratory distress syndrome. Anesth. Analg. (Cleve), 52: 328 (1973).

12. Enhörning, G.: Pulsating bubble technique for evaluating pulmonary surfactant. J. Appl. Physiol.: Resp. Environ. Exercise Physiol., 43: 198 (1977).

13. Enhörning, G., Grossmann, G., and Robertson, B.: Tracheal deposition of surfactant before the first breath. Am. Rev. Respir. Dis., 107: 921 (1973).

14. Enhörning, G., Hill, D., Sherwood, G., Cutz, E., Robertson, B., and Bryan, C.: Improved ventilation or prematurely delivered primates following tracheal deposition of surfactant. Amer. J. Obs. Gynecol., 132: 529 (1978).

15. Enhörning, G. and Robertson, B.: Lung expansion in the premature rabbit fetus after tracheal deposition of surfactant. Pediatrics, 50: 58 (1972).

16. Fujiwara, T. and Adams, F. H.: Surfactant for hyaline membrane disease Pediatrics, 66: 795 (1980)

17. Fujiwara, T., Higuchi, M., and Kushima, K.: Antenatal diagnosis of fetal lung maturity and idiopathic respiratory distress syndrome by estimation of pulmonary surfactant in the amniotic fluid. In: A. Mistretta, G. Ascani, Eds.: Gli effetti della citicolina (cdp-colina) in pneumologia. pp. 56-68 (Edizione Minerva Medica, Torino, 1974)

18. Fujiwara. T., Maeta, H., Chida, S., Morita, T., Watabe, Y., and Abe, T.: Artificial surfactant therapy in hyaline-membrane disease. Lancet, $1: 55$ (1980).

19. Fujiwara, T., Tanaka, Y., and Takei, Y.: Surface properties of artificial surfactant in comparison with natural and synthetic surfactant lipids. IRCS Med. Sci., 7: 311 (1979)

20. Gruenwald, P.: Surface tension as a factor in the resistance of neonatal lungs to aeration. Amer. J. Obs. Gynecol., 53: 996 (1947).

21. Herman, S. and Reynolds, E. O. R.: Methods for improving oxygenation in infants ventilated for severe hyaline membrane disease. Arch. Dis. Child., 48: $612(1973)$.

22. Ikegami, M.. Adams. F. H., Towers, B., and Osher, A.: The quantity of natural surfactant necessary to prevent the respiratory distress syndrome in premature lambs. Pediatr. Res., 14: 1082 (1980).

23. Lachmann, B., Grossmann, G., Freyse, J., and Robertson, B.: Lung-thorax compliance in the artificially ventilated premature rabbit neonate in relation to variations in inspiration: expiration ratio. Pediatr. Res., 15: 833 (1981).
24. Lachmann. B., Grossmann, G.. Nilsson, R., and Robertson. B.: Lung mechanics during spontaneous ventilation in premature and fullterm rabbit neonates. Respir. Physiol., 38: 283 (1979).

25. Lachmann, B., Tischer, A-M.. Grossmann, G.. and Robertson, B.: Lung compliance and alveolar expansion in the artificially ventilated premature newborn rabbit after maternal treatment with Ambroxol. Respiration, 42: 209 (1981).

26. Lowry, O. H., Rosebrough, N. J., Farr. A. L., and Randall, R. J.: Protein measurement with the folin phenol reagent. J. Biol. Chem., 193:265 (1951)

27. Nilsson, R.. Grossmann, G., and Robertson, B.: Lung surfactant and the pathogenesis of neonatal bronchiolar lesions induced by artificial ventilation. Pediatr. Res.. 12: 249 (1978).

28. Nilsson, $R$, Grossmann, $G$, and Robertson. B : Artificial ventilation of premature newborn rabbits: effects of positive end-expiratory pressure on lung mechanics and lung morphology. Acta Paediatr. Scand., 69: 597 (1980).

29. Nilsson, R., Grossmann, G., and Robertson, B.: Bronchiolar epithelial lesions induced in the premature rabbit neonate by short periods of artificial ventilation. Acta Path. Microbiol. Scand. [A], 88: 359 (1980).

30. Nilsson, R., Grossmann, G., and Robertson, B.: Pathogenesis of neonatal lung lesions induced by artificial ventilation: evidence against the role of barotrauma. Respiration, 40: 218 (1980).

31. Renkonen, O. and Luukonen, A.: Thin-layer chromatography of phospholipids and glycolipids. In: G. V. Marinetti. Ed.: Lipid chromatographic analysis, Vo 1, pp. 1-58 (Marcel Dekker. New York, 2nd Ed., 1976).

32. Reynolds, E. O. R.: Effect of alterations in mechanical ventilator setting on pulmonary gas exchange in hyaline membrane disease. Arch. Dis. Child., 46 : 152 (1971).

33. Reynolds, E. O. R. and Taghizadeh, A.: Improved prognosis of infants mechanically ventilated for hyaline membrane disease. Arch. Dis. Child., 49: 505 (1974)

34. Robertson, B.: Current and counter-current theories on lung surfactant. Scand. J. Resp. Dis., 57: 199 (1976).

35. Robertson, B.: Surfactant substitution. Experimental models and clinical applications. Lung, 158: 57 (1980).

36. Robertson, B.: Review of experimental hyaline membrane disease. Diagn. Histopathol., 4: 49 (1981)

37. Strang. L. B.: Neonatal respiration. p. 181. Blackwell, Oxford (1977).

38. The protein content of surfactant was determined by Fil. Kand. Örjan Tollbom, Stockholm.

39. Miss Maria Agnedal, Stockholm, provided skillful technical assistance in the phospholipid analyses.

40. Address for correspondence and reprint requests: Dr. Bengt Robertson, Department of Pathology, St. Görans Hospital, S-112 81 Stockholm, Sweden.

41. This work was supported by the Swedish Medical Research Council (Project No. 3351), The Swedish National Association against Heart and Chest Diseases, Karolinska Institutets Fonder, and the Royal Swedish Academy of Sciences.

42. Received for publication November 4, 1981 .

43. Accepted for publication April 1. 1982. 